\title{
5-azacytidine induces transcriptome changes in Escherichia coli via DNA methylation-dependent and DNA methylation-independent mechanisms
}

\author{
Kevin T. Militello ${ }^{1 *}$, Robert D. Simon', Alexandra H. Mandarano ${ }^{1,2}$, Anthony DiNatale ${ }^{1}$, Stacy M. Hennick',
} Justine C. Lazatin ${ }^{1}$ and Sarah Cantatore

\begin{abstract}
Background: Escherichia coli K-12 strains contain DNA cytosine methyltransferase (Dcm), which generates 5-methylcytosine at 5'CCWGG3' sites. Although the role of 5-methylcytosine in eukaryotic gene expression is relatively well described, the role of 5-methylcytosine in bacterial gene expression is largely unknown.

Results: To identify genes that are controlled by 5-methylcytosine in E. coli, we compared the transcriptomes of cells grown in the absence and presence of the DNA methylation inhibitor 5-azacytidine. We observed expression changes for 63 genes. The majority of the gene expression changes occurred at early stationary phase and were up-regulations. To identify gene expression changes due to a loss of DNA methylation, we compared the expression of selected genes in a wild-type and $\mathrm{dcm}$ knockout strain via reverse transcription quantitative PCR.

Conclusions: Our data indicate that 5-azacytidine can influence gene expression by at least two distinct mechanisms: DNA methylation loss and a mechanism that is independent of DNA methylation loss. In addition, we have identified new targets of 5-methylcytosine-mediated regulation of gene expression. In summary, our data indicate that 5-azacytidine impacts the composition of the bacterial transcriptome, and the primary effect is increased gene expression at early stationary phase.
\end{abstract}

Keywords: Stationary phase, 5-azacytidine, DNA methylation inhibitor, DNA methylation, 5-methylcytosine, Dcm, RpoS, Escherichia coli, Sodium bisulfite sequencing, DNA microarray

\section{Background}

The modified DNA base 5-methylcytosine (5-MeC) plays an important role in transcriptional regulation in higher eukaryotes. The presence of $5-\mathrm{MeC}$ in eukaryotic promoters and $\mathrm{CpG}$ islands is generally repressive for transcription, whereas $5-\mathrm{MeC}$ in gene bodies is positively correlated with transcription [1]. Bacteria, such as $E$. coli, contain 5-MeC [2]. In E. coli $\mathrm{K}-12$ strains, the only known cytosine-5 DNA methyltransferase is DNA cytosine methyltransferase $(\mathrm{Dcm})[3,4]$. Dcm methylates the second cytosine in 5'CCWGG3' sequences [3]. The $\mathrm{dcm}$

\footnotetext{
* Correspondence: militello@geneseo.edu

'State University of New York at Geneseo, ISC 357, 1 College Circle, Geneseo, NY 14454, USA

Full list of author information is available at the end of the article
}

gene is in an operon with the $v s r$ gene which codes for a protein that repairs T:G mismatches caused by deamination of 5-MeC [5-7]. The original function elucidated for Dcm was in restriction enzyme biology where Dcm promotes the loss of plasmids containing the EcoRII restriction enzyme gene (which cleaves 5' CCWGG3' sites) and protects cells from post-segregational killing by the EcoRII restriction enzyme [8, 9]. In addition, Dcm protects phage lambda against DNA cleavage when EcoRII is introduced into the cell [10]. However, Dcm is a solitary methyltransferase without a cognate restriction enzyme in K-12 cells. Other roles for Dcm are certainly possible.

Based on the important role of $5-\mathrm{MeC}$ in eukaryotic transcription and the fact that there is little known about 
the relationship between $5-\mathrm{MeC}$ and gene expression in bacteria, Dcm has been recently evaluated for an impact on the composition of the E. coli transcriptome. Our group has demonstrated that two ribosomal protein genes and the drug resistance transporter gene $\operatorname{sugE}$ are upregulated in the absence of the $\mathrm{dcm}$ gene at early stationary phase via reverse-transcription quantitative PCR (RT-qPCR) [11, 12]. Kahramanoglou et al. demonstrated that there are gene expression changes in $\mathrm{dcm}$ knockout cells using DNA microarrays, and most changes are at stationary phase [13]. Taken together, these data suggest that $\mathrm{Dcm}$ influences the transcriptome. As the only known function of Dcm is cytosine DNA methylation, the simplest model is that Dcm mediates gene expression changes via the generation of $5-\mathrm{MeC}$. It is noteworthy that some DNA methyltransferases can methylate tRNA and influence gene expression via a DNA-methylation independent mechanism [14-16].

In order to test the model that Dcm-mediated cytosine DNA methylation directly influences gene expression in E. coli and identify new genes impacted by DNA methylation, we analyzed the $E$. coli transcriptome in the absence and presence of 5-azacytidine (5-azaC) treatment. 5 -azaC is a nucleoside analog that is used clinically to treat myelodysplastic syndromes [17]. 5-azaC is phosphorylated upon cell entry and incorporated into both RNA and DNA $[18,19]$. When 5 -azaC is incorporated into DNA, cytosine-5 DNA methyltransferases become covalently trapped on the DNA and are degraded, and this limits the amount of enzyme available for the generation of $5-\mathrm{MeC}[18,19]$. Thus, 5 -azaC is a cytosine DNA methylation inhibitor. It is important to note that 5-azaC has effects on the cell beyond blocking DNA methylation. For example, 5-azaC can induce the SOS response [20, 21], induce DNA mutations [22], block translation [23], and block RNA methylation [24]. Thus, the physiology of 5-azaC treated cells is not identical to cells lacking cytosine DNA methyltransferases. Although 5 -azaC has been routinely used to demethylate DNA in a variety of eukaryotes to assess the consequences of cytosine DNA methylation loss $[25,26]$, this is the first report of the response of the entire transcriptome to 5$\mathrm{azaC}$ in a bacterial organism.

\section{Results}

\section{Effects of 5-azaC on global DNA methylation levels}

First, we determined the concentration dependence of DNA methylation inhibition by 5 -azaC using digestion of DNA with the restriction enzyme isoschizomers BstNI and PspGI (Fig. 1). Both enzymes cut DNA at Dcm recognition sites ( $\left.5^{\prime} \mathrm{CCWGG} 3^{\prime}\right)$, but PspGI is blocked by Dcm-mediated methylation of the second cytosine. In the absence of 5-azaC, DNA from early stationary phase cells was largely resistant to PspGI indicating that the DNA is heavily methylated at this stage. At early logarithmic stage, DNA was slightly sensitive to PspGI, indicating that most but not all 5'CCWGG3' sites are methylated. These data are consistent with our current

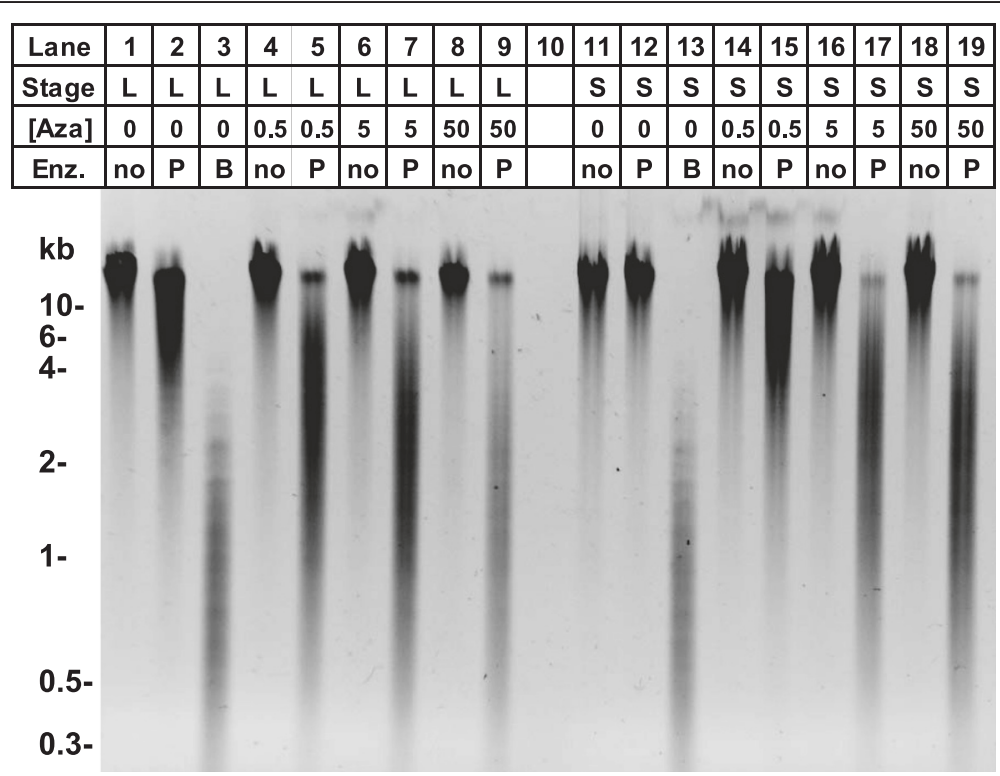

Fig. 1 The effect of 5-azaC on global DNA methylation levels in Escherichia coli. E. coli wild-type strain BW25113 was grown in LB at $37^{\circ} \mathrm{C}$ in the absence of 5-azaC, the presence of $0.5 \mu \mathrm{g} / \mathrm{mL} 5$-azaC, $5 \mu \mathrm{g} / \mathrm{mL}$ 5-azaC, and $50 \mu \mathrm{g} / \mathrm{mL}$ 5-azaC. At two hours (logarithmic phase, L) and eight hours (early stationary phase, S), genomic DNA was isolated. DNA was incubated in the absence of restriction enzyme, presence of BstNI (B) (not blocked by Dcm methylation), or presence of PspGI (P) (blocked by Dcm methylation). DNA samples were analyzed by agarose gel electrophoresis and ethidium bromide staining 
results (Fig. 3) indicating that there is $100 \%$ methylation of a single osmE 5'CCWGG3' site analyzed by sodium bisulfite sequencing from early stationary phase DNA and $93.3 \%$ methylation of a single osmE 5'CCWGG3' site analyzed by sodium bisulfite sequencing from logarithmic phase DNA. The data are also consistent with previously published results indicating stationary phase DNA is heavily methylated, whereas logarithmic phase DNA is methylated but has some unmethylated sites $[13,27]$. It is currently unclear if the lack of $100 \%$ methylation at logarithmic phase is due to active DNA replication where newly synthesized DNA is unmethylated or regulation of DNA methylation. When DNA was isolated from cells incubated in the presence of 5azaC, the DNA was more sensitive to digestion with PspGI, indicating 5-azaC inhibits DNA methylation at all concentrations used at both phases. There was an increase in PspGI sensitivity as the concentration moved from $0.5 \mu \mathrm{g} / \mathrm{mL} 5$-azaC to $5 \mu \mathrm{g} / \mathrm{mL} 5$-azaC, especially in early stationary phase DNA.

\section{Effects of 5-azaC on bacterial growth}

We conducted experiments to determine the effects of 5 -azaC on the kinetics of E. coli growth (Fig. 2). Bacterial cells were grown in the absence of 5 -azaC and three concentrations of the drug as described previously. There was little effect of 5-azaC on bacterial growth for the first few hours. At two hours, which represents logarithmic phase and one time point for the DNA microarray analysis, ANOVA indicated that there is not a statistically significant difference in $\mathrm{A}_{600}$ readings between the four cultures $(p=8.3 \mathrm{E}-2)$. This is likely due to the fact that 5 -azaC has to be transported into the cells, phosphorylated, and incorporated into nucleic acids before it is active. After $8 \mathrm{~h}$ of growth in 5 -azaC (early stationary phase), ANOVA indicated there was a statistically significant difference in $\mathrm{A}_{600}$ readings $(p=$ 9.9E-5). Post hoc analysis indicated that there was no difference in $\mathrm{A}_{600}$ readings between untreated cultures and cultures grown in $0.5 \mu \mathrm{g} / \mathrm{mL} 5$-azaC $(p=1.4 \mathrm{E}-1)$. However, there was a statistically significant difference between untreated cultures and cultures grown in $5 \mu \mathrm{g} /$ $\mathrm{mL} 5$-azaC $(p=4.7 \mathrm{E}-3)$ and $50 \mu \mathrm{g} / \mathrm{mL} 5$-azaC $(p=7.6 \mathrm{E}-$ $5)$. In summary, the data are consistent with previous experiments indicating that high concentrations of 5-azaC can inhibit bacterial growth [28-30]. Based on the PspGI digestion data and the growth curve data above, we chose $5 \mu \mathrm{g} / \mathrm{mL}$ as our working concentration of 5 -azaC. At $5 \mu \mathrm{g} / \mathrm{mL}$, there is an obvious reduction of DNA methylation, and the reduction is greater than that

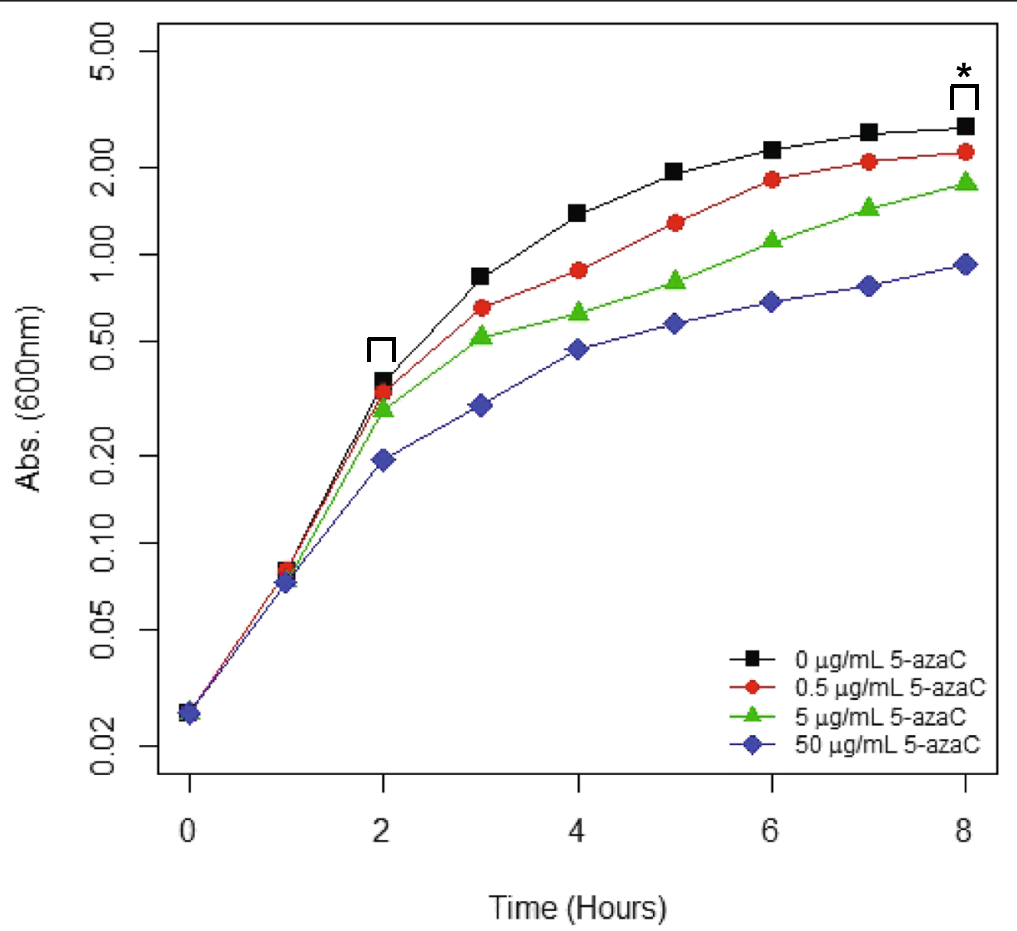

Fig. 2 The effect of 5-azaC on Escherichia coli growth in liquid media. E. coli wild-type strain BW25113 was grown in $L B$ at $37^{\circ} \mathrm{C}$ in the absence of 5-azaC (black squares), the presence of $0.5 \mu \mathrm{g} / \mathrm{mL}$ 5-azaC (red circles), $5 \mu \mathrm{g} / \mathrm{mL}$ 5-azaC (green triangles) and $50 \mu \mathrm{g} / \mathrm{mL}$ 5-azaC (blue diamonds) for eight hours. At every hour, each culture was analyzed by spectrophotometry at $600 \mathrm{~nm}$. The data are from three biological replicates $(n=3)$. Error bars representing standard deviation are not shown to maintain clarity of the four lines. Brackets indicate time points of RNA isolation for microarray analysis, and data analyzed by ANOVA. The asterisk indicates a p-value of $<0.05$ 
observed using $0.5 \mu \mathrm{g} / \mathrm{mL}$ 5-azaC. With respect to growth defects, the growth defect with $5 \mu \mathrm{g} / \mathrm{mL} 5$-azaC is less than that observed using $50 \mu \mathrm{g} / \mathrm{mL} 5$-azaC. A severe growth defect could compromise the interpretation of downstream DNA microarray experiments.

\section{Effects of 5-azaC on site specific methylation}

The PspGI assay described above to monitor DNA methylation is primarily qualitative. To better quantify the ability of 5-azaC to block DNA methylation in Escherichia coli, we analyzed the osmE promoter region for $5-\mathrm{MeC}$ from cells grown in the absence and presence of $5 \mu \mathrm{g} / \mathrm{mL} 5$-azaC using sodium bisulfite sequencing. Treatment of DNA with sodium bisulfite causes the deamination of cytosines to uracils, but 5$\mathrm{MeCs}$ are not deaminated and remain as cytosines in DNA sequencing reactions [31]. OsmE was chosen as it contains one $5^{\prime} \mathrm{CCWGG3'}$ site in its promoter. The sodium bisulfite sequencing data are shown in Fig. 3. At the second cytosine in the single 5'CCWGG3' site in the DNA analyzed, $93.3 \%$ of the logarithmic phase cytosines and $100 \%$ of the early stationary phase cytosines were resistant to bisulfite conversion. At the remaining 34 non-5'CCWGG3' sites, only $3.3 \%$ of the logarithmic phase cytosines and $2.6 \%$ of the early stationary phase cytosines were resistant to bisulfite conversion. The data are consistent with the model that Dcm methylates 5'CCWGG3' sites. Low levels of non-5'CCWGG3' methylation are most easily explained by a very low level of non-conversion of cytosines to uracil, which is always observed in bisulfite sequencing reactions. However, it is not possible to rule out low levels of non-5'CCWGG3' methylation. In the presence of 5-azaC, the level of methylation at the 5'CCWGG3' site was reduced from $93.3 \%$ to $28.6 \%$ at logarithmic phase and from $100 \%$ to $50 \%$ at early stationary phase. The potency of 5 -azaC at early logarithmic phase is likely due to better incorporation of the drug into DNA during DNA replication at this stage, yet there is inhibition at early stationary phase as well. In summary, the data demonstrate that $5 \mu \mathrm{g} / \mathrm{mL} 5$-azaC blocks, but does not eliminate, DNA methylation at $5^{\prime} \mathrm{CCWGG3}$ ' sites in E. coli.

\section{Transcriptome changes in 5-azaC treated cells}

We compared E. coli transcriptomes in the absence and presence of 5-azaC using DNA microarray analysis of logarithmic phase and early stationary phase RNAs (Additional files 1 and 2). Overall, we detected six upregulated genes and one down-regulated gene at logarithmic phase (Table 1), and 44 up-regulated genes and 12 down-regulated genes at early stationary phase (Table 2). To confirm the validity of the microarray experiments, we analyzed expression of the recA and $r s m I$ genes in 5-azaC treated cells via RT-qPCR (Table 3). The RT-qPCR experiments confirmed the direction of the changes observed in the microarray experiments; the RT-qPCR fold-changes were slightly higher.

At logarithmic phase, the most obvious changes are genes that respond to DNA damage such as $\operatorname{rec} N$, $\operatorname{din} D$, $\operatorname{din} B$, and $\operatorname{din} G$. DAVID analysis indicates that the DNA repair and SOS response functional categories are overrepresented in this list (Table 4). We used a moderately stringent cut off for gene expression changes and there are other up-regulated SOS genes that have a $\mathrm{p}$ value $<0.05$, but did not make the FDR cutoff. One example is recA, which was shown to be up-regulated by RT-qPCR (Table 3). To determine if the gene expression changes are due to a direct effect of 5-azaC or loss of DNA methylation, we analyzed expression of $r e c A$ and $r s m I$ in a $d c m$ knockout strain. $\operatorname{Rec} A$ expression did not change in the $d c m$ knockout strain indicating 5-azaC-dependent recA gene expression changes are not due to a loss of DNA methylation. However, expression of rsmI, a $16 \mathrm{~S}$ rRNA methyltransferase, was increased in the $\mathrm{dcm}$ knockout strain, indicating $r s m I$ expression is influenced by $\mathrm{Dcm}$.

We further inspected the data for expression of DNA repair pathway genes in the presence of 5 -azaC. The need for DNA repair after 5-azaC treatment is predicted to be due to the formation of DNA-Dcm crosslinks, as Dcm overexpression strains display increased sensitivity to 5 -azaC induced killing $[21,28,29,32]$. In addition, DNA repair may result in synthesis of new unmethylated DNA and explain methylation-dependent gene expression changes. At logarithmic phase, there is little evidence for 5-azaC induced expression of the mismatch repair genes $m u t S, m u t H$, and $m u t L$, nucleotide excision repair pathway genes $u v r A, u v r B$, and $u v r C$, and pyrimidine base excision repair genes ung, nth, mug, and mutM (Table 1). We cannot rule out induction under conditions that were not evaluated. We did observe upregulation of one gene that functions in translesion synthesis $(\operatorname{din} B)$. The significance of increased $\operatorname{din} B$ expression is unclear. Translesion synthesis is not thought to be required for 5-azaC induced DNA-protein crosslink repair as translesion mutants do not display increased sensitivity to the drug $[21,30,32,33]$. Interestingly, three of the seven genes in Table 1 have a defined or predicted role in homologous recombination $(r e c N$, $r m u C, \operatorname{din} G$ ). Homologous recombination is thought to be the main pathway required for repair of 5-azaC induced damage as homologous recombination mutants are more sensitive to 5 -azaC than wild-type strains [21, 28, 30, 32-34]. Thus, our data are consistent with a model where 5 -azaC induced damage is repaired by homologous recombination, and components of this pathway are upregulated in 5-azaC treated cells. 


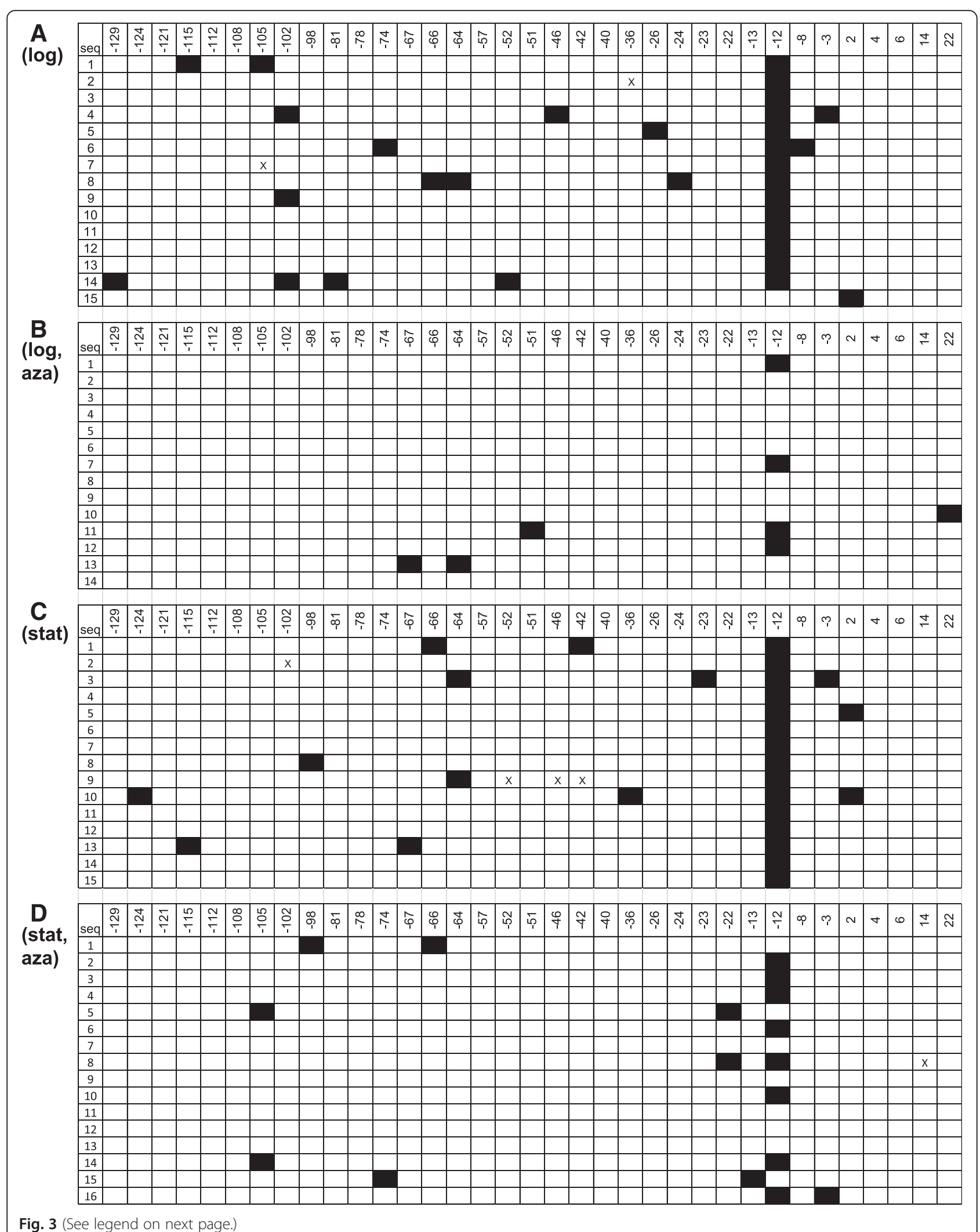


(See figure on previous page.)

Fig. 3 5-azaC reduces cytosine DNA methylation of the osmE promoter in Escherichia coli. E. coli wild-type strain BW25113 was grown in LB at $37^{\circ} \mathrm{C}$ in the absence of 5 -azaC and presence of $5 \mu \mathrm{g} / \mathrm{mL} 5$-azaC. DNA was isolated after two hours (logarithmic phase) and eight hours (early stationary phase). DNA samples were treated with sodium bisulfite. The osmE locus was amplified by PCR using sodium bisulfite-treated DNA as a template. PCR products were inserted into the plasmid pGEM-T Easy, and analyzed by Sanger sequencing. a) logarithmic phase DNA in untreated cells, b) logarithmic phase DNA in 5-azaC treated cells, $\mathbf{c}$ ) early stationary phase DNA in untreated cells, and $\mathbf{d}$ ) early stationary phase DNA in 5-azaC treated cells. The numbers represent the position of the cytosines with respect to the transcription start site (+1). The cytosines in the 5'CCWGG3' site are at positions -13 and -12 . Open boxes represent Cs in the osmE sequence (Ts after bisulfite sequencing), and closed boxes represent 5-MeCs in the osmE sequence (Cs after bisulfite sequencing). Rows represent different clones. Xs represent ambiguous sequence information

At early stationary phase, there are 56 differentially expressed genes. Interestingly, the early stationary phase gene list is completely different from the logarithmic phase list (Tables 1 and 2). DAVID analysis identified functional categories ribosome and organelle inner membrane as overrepresented in the early stationary phase list (Table 4). Ribosomal protein genes have previously been reported as up-regulated in the $d \mathrm{~cm}$ knockout strain $[12,13]$ and the organelle inner membrane list contains sugE, which has previously been reported to be up-regulated in the absence of $\mathrm{dcm}$ [11]. To identify new target genes impacted by cytosine DNA methylation, we analyzed a few targets in the $d c m$ knockout strain via RT-qPCR (Table 3). We investigated osmE via RT-qPCR as it has a $5^{\prime}$ CCWGG3' site in its promoter (Fig. 3). OsmE expression decreases in the $d c m$ knockout strain at early stationary phase, indicating Dcm influences osmE expression. OsmE was also down-regulated in the $d c m$ knockout strain at stationary phase via RTqPCR. Interestingly, osmE is the first example of a gene that is dependent upon Dcm for maximal expression. The expression of $a t p H$, a subunit of ATP synthase, did not change in the $d c m$ knockout strain, indicating the 5-azaC-dependent gene expression change is not due to a loss of DNA methylation. FimA, a fimbria subunit, was upregulated in the $d c m$ knockout strain indicating control by $\mathrm{Dcm}$. The expression of the $\operatorname{csp} B$ gene, a cold shock protein, increased in the $d c m$ knockout strain, but not to the extent observed with 5 -azaC treatment. Thus, $\operatorname{csp} B$ may respond to both the loss of DNA methylation and a 5-azaC-dependent DNA methylationindependent mechanism.

\section{Discussion}

At logarithmic phase, the $d c m$ gene is expressed as detected by microarray analysis and the DNA is methylated at $5^{\prime} \mathrm{CCWGG3}$ sites (Figs. 1 and 3). Yet there are very few 5 -azaC-induced gene expression changes in the wild-type strain. The majority of 5 -azaC changes are in DNA repair protein genes and are likely due to DNA damage and activation of the SOS response rather than a loss of DNA methylation (Table 4). 5-azaC-dependent activation of the SOS response has been reported [20, 21 , and the pathway promotes survival in the presence of 5-azaC [20,21, 28, 30,32-34]. Although it is possible that we are missing $d c m$-dependent changes due to a moderately stringent statistical cutoff and/or the lack of $100 \%$ methylation inhibition via 5 -azaC, a simple model based on our data and three recent articles is that Dcm has only a minor effect on the logarithmic stage transcriptome [11-13]. It is noteworthy that the effect of Dcm on the transcriptome has only been tested under standard conditions (rich medium, $37{ }^{\circ} \mathrm{C}$, aerobic, laboratory strain), and future work will evaluate other conditions.

At early stationary phase, the $d c m$ gene is expressed as detected by microarray analysis, the DNA is methylated at 5'CCWGG3' sites, and there are numerous 5-azaCdependent gene expression changes. Not all of the genes induced by 5 -azaC at stationary phase are predicted to

Table 1 Gene expression changes in logarithmic phase, 5-azacytidine-treated Escherichia coli cells

\begin{tabular}{|c|c|c|c|c|}
\hline $\begin{array}{l}\text { Gene } \\
\text { ID }\end{array}$ & Name & Description & $\begin{array}{l}\text { fold change } \\
(\log 2)\end{array}$ & $\mathrm{p}$ \\
\hline b2616 & $\operatorname{rec} N$ & Recombination and repair & 2.76 & $2.52 \mathrm{E}-04$ \\
\hline b3645 & $\operatorname{din} D$ & DNA-damage-inducible protein, function unknown & 2.24 & 2.20E-05 \\
\hline b3146 & rsml & 165 rRNA C1402 2'-O-ribose methyltransferase, SAM-dependent & 1.82 & $5.84 \mathrm{E}-05$ \\
\hline b0231 & $\operatorname{din} B$ & $\begin{array}{l}\text { DNA polymerase IV, capable of translesion synthesis; overexpression enhances mutagenesis; mediates } \\
\text { targeted mutagenesis by 4-NQO; intrinsic AP lyase activity }\end{array}$ & 1.52 & 2.28E-04 \\
\hline b3832 & rmuC & DNA recombination protein; mutants have elevated recombination at microhomologies & 1.30 & 3.36E-05 \\
\hline b0799 & $\operatorname{din} G$ & ATP-dependent DNA helicase; putative repair and recombination enzyme, monomeric & 1.05 & 1.74E-04 \\
\hline b2876 & yqec & Putative selenium-dependent hydroxylase accessory protein & -1.13 & 7.92E-05 \\
\hline
\end{tabular}


Table 2 Gene expression changes in early stationary phase, 5-azacytidine-treated Escherichia coli cells

\begin{tabular}{|c|c|c|c|c|}
\hline Gene ID & Name & Description & fold-change (log2) & $\mathrm{p}$ \\
\hline b1557 & $\operatorname{csp} B$ & Cold shock protein, Qin prophage; cold shock inducible & 3.40 & $7.28 \mathrm{E}-04$ \\
\hline b2699 & recA & $\begin{array}{l}\text { Multifunctional DNA recombination and repair protein; ssDNA-dependent ATPase; } \\
\text { synaptase; ssDNA and dsDNA binding protein forming filaments; ATP-dependent homologous } \\
\text { DNA strand exchanger; recombinase A; LexA autocleavage cofactor }\end{array}$ & 2.53 & 4.87E-05 \\
\hline b3175 & $\sec G$ & $\begin{array}{l}\text { SecYEG inner membrane translocon secA-interacting subunit; } \\
\text { preprotein translocase secAYEG subunit }\end{array}$ & 2.43 & $3.43 \mathrm{E}-04$ \\
\hline b4177 & purA & Adenylosuccinate synthase, purine synthesis & 2.37 & $6.70 \mathrm{E}-04$ \\
\hline b4314 & $\operatorname{fim} A$ & Fimbrin type 1, major structural subunit; phase variation & 2.11 & 1.33E-03 \\
\hline b3231 & rp/M & $50 S$ ribosomal subunit protein L13; binds Zn(II) & 2.00 & $1.12 \mathrm{E}-03$ \\
\hline b3186 & rp/U & $50 S$ ribosomal subunit protein $\mathrm{L} 21$ & 1.92 & $5.10 \mathrm{E}-04$ \\
\hline b3230 & rpsl & $30 S$ ribosomal subunit protein $\$ 9$ & 1.77 & 3.95E-04 \\
\hline b3739 & atpl & ATP synthase, membrane-bound accessory factor & 1.68 & 7.67E-04 \\
\hline b0406 & tgt & tRNA-guanine transglycosylase; queuosine biosynthesis; zinc metalloprotein & 1.66 & $1.97 \mathrm{E}-03$ \\
\hline b3735 & atpH & ATP synthase subunit delta, membrane-bound, F1 sector & 1.66 & $1.70 \mathrm{E}-03$ \\
\hline b4200 & rpsF & 30 S ribosomal subunit protein S6; suppressor of dnaG-Ts & 1.64 & $2.18 \mathrm{E}-03$ \\
\hline b3409 & $f e o B$ & Putative ferrous iron permease with GTP-binding domain & 1.62 & 3.37E-03 \\
\hline b3810 & yigA & DUF484 family protein, function unknown & 1.57 & $2.66 \mathrm{E}-03$ \\
\hline b0926 & $y c b k$ & Periplasmic M15A family non-protease, function unknown & 1.56 & $8.53 \mathrm{E}-04$ \\
\hline b0927 & $y c b l$ & Glyoxalase II homolog, function unknown & 1.56 & 3.57E-03 \\
\hline b3704 & $r n p A$ & RNase P, C5 protein component; involved in tRNA and 4.5S RNA-processing & 1.56 & $2.51 \mathrm{E}-03$ \\
\hline b3342 & $r p s L$ & 30 S ribosomal subunit protein S12; RNA chaperone & 1.54 & 2.60E-05 \\
\hline b4238 & $n r d D$ & Ribonucleoside-triphosphate reductase; class III anaerobic ribonucleotide reductase & 1.54 & $1.83 \mathrm{E}-03$ \\
\hline b1147 & ymfL & Function unknown, e14 prophage & 1.53 & 1.66E-03 \\
\hline b2150 & $m g / B$ & $\begin{array}{l}\text { D-galactose-, D-glucose-binding protein, periplasmic; } \\
\text { substrate recognition for transport and chemotaxis; binds calcium }\end{array}$ & 1.45 & $2.24 \mathrm{E}-03$ \\
\hline b4148 & sugE & Multidrug efflux pump; overexpression resistance to cetylpyridinium & 1.44 & $1.22 \mathrm{E}-03$ \\
\hline b3983 & $r p / K$ & $50 S$ ribosomal subunit protein $L 11$; kasugamycin sensitivity & 1.44 & $2.33 \mathrm{E}-03$ \\
\hline b0118 & $a c n B$ & Aconitate hydratase 2; aconitase B; 2-methyl-cis-aconitate hydratase; iron-sulfur cluster; monomeric & 1.42 & 1.80E-03 \\
\hline b0407 & yajC & $\begin{array}{l}\text { SecDFyajC membrane secretion complex subunit; } \\
\text { assists the SecYE translocon to interact with SecA and export proteins }\end{array}$ & 1.41 & 2.23E-03 \\
\hline b3357 & $c r p$ & CAMP-activated global transcription factor; mediator of catabolite repression; CRP; CAP & 1.40 & 1.49E-04 \\
\hline b2796 & sdaC & L-serine:H+ symport permease, threonine-insensitive & 1.40 & 1.84E-03 \\
\hline b3637 & $\operatorname{rpm} B$ & $50 S$ ribosomal subunit protein $L 28$ & 1.38 & 9.87E-05 \\
\hline b3508 & yhid & Predicted $\mathrm{Mg}(2+)$ transport ATPase, MgtC family, function unknown; inner membrane protein & 1.35 & $2.62 \mathrm{E}-03$ \\
\hline b3339 & tufA & $\begin{array}{l}\text { Translation elongation factor EF-Tu 1; GTP-dependent binding of aa-tRNA to the A-site of ribosomes; } \\
\text { has intrinsic GTPase activity when bound to kirromycin }\end{array}$ & 1.33 & $3.21 \mathrm{E}-03$ \\
\hline b3985 & rplJ & $50 S$ ribosomal subunit protein $L 10$; streptomycin resistance & 1.30 & $3.36 \mathrm{E}-03$ \\
\hline b0428 & CyoE & Cytochrome o oxidase protoheme IX farnesyltransferase subunit & 1.26 & $8.29 \mathrm{E}-04$ \\
\hline b0174 & $i s p U$ & Undecaprenyl pyrophosphate synthase; dimeric & 1.22 & 1.14E-04 \\
\hline b0756 & galm & Aldose 1-epimerase, type-1 mutarotase; galactose mutarotase; monomeric & 1.21 & $1.92 \mathrm{E}-03$ \\
\hline b0946 & $z a p C$ & FtsZ stabilizer & 1.19 & 1.47E-04 \\
\hline b2279 & nuok & NADH:ubiquinone oxidoreductase subunit K, complex I; NADH dehydrogenase I & 1.15 & 2.64E-04 \\
\hline b0388 & arol & Shikimate kinase ॥ & 1.12 & $6.85 \mathrm{E}-04$ \\
\hline b4237 & $n r d G$ & Ribonucleotide reductase activase, generating glycyl radical; contains iron; binds NrdD tightly & 1.11 & 4.09E-04 \\
\hline b4016 & acek & Isocitrate dehydrogenase kinase/phosphatase & 1.11 & 1.10E-03 \\
\hline b1847 & yebF & Extracellular Colicin M immunity family protein; function unknown & 1.08 & 5.59E-04 \\
\hline
\end{tabular}


Table 2 Gene expression changes in early stationary phase, 5-azacytidine-treated Escherichia coli cells (Continued)

\begin{tabular}{|c|c|c|c|c|}
\hline b3961 & oxyR & Oxidative and nitrosative stress transcriptional regulator & 1.08 & 2.03E-03 \\
\hline b0463 & $a c r A$ & $\begin{array}{l}\text { AcrAB-TolC multidrug efflux pump; additionally dye, detergent, solvent resistance; } \\
\text { membrane-fusion lipoprotein }\end{array}$ & 1.06 & 2.36E-04 \\
\hline b3255 & $a c c B$ & Acetyl-CoA carboxylase, biotin carboxyl carrier protein; BCCP; homodimeric & 1.05 & $6.41 \mathrm{E}-04$ \\
\hline b0083 & ftsL & Cell division and growth, membrane protein & 1.01 & 9.70E-04 \\
\hline b1195 & $y m g E$ & UPF0410 family predicted inner membrane protein; function unknown & -1.01 & 2.15E-03 \\
\hline b0255 & $\operatorname{ins} N^{\prime}$ & Pseudogene reconstruction, fused IS911 transposase AB & -1.08 & 2.42E-04 \\
\hline b4107 & $y j d N$ & Metalloprotein superfamily protein, function unknown & -1.30 & 4.90E-04 \\
\hline b1223 & nark & Nitrate/nitrite antiporter; promotes nitrite extrusion and uptake & -1.31 & 3.47E-03 \\
\hline b1739 & osmE & Osmotically inducible lipoprotein, function unknown & -1.46 & $1.01 \mathrm{E}-03$ \\
\hline b0836 & bssR & $\begin{array}{l}\text { Repressor of biofilm formation by indole transport regulation; } \\
\text { global regulator. e.g. of Al-2 transport and motility genes }\end{array}$ & -1.52 & 5.23E-05 \\
\hline b1795 & yeaQ & UPF0410 family protein, function unknown & -1.56 & $1.65 \mathrm{E}-03$ \\
\hline b2414 & cysk & $\begin{array}{l}\text { Cysteine synthase A, O-acetylserine sulfhydrylase A; } \\
\text { homodimeric; selenate, azaserine, chromate resistance; } \\
\text { alkali-inducible, sulfate starvation-inducible protein SSI5; cysteine desulfhydrase }\end{array}$ & -1.58 & 2.86E-03 \\
\hline b0806 & $m c b A$ & $\begin{array}{l}\text { Stimulates colanic acid mucoidy, YhcN family, periplasmic; suppresses biofilm formation; } \\
\text { repressed by McbR }\end{array}$ & -1.71 & $5.11 \mathrm{E}-04$ \\
\hline b2425 & cys $P$ & Thiosulfate-binding protein, periplasmic & -1.84 & 1.90E-04 \\
\hline b0506 & allR & Repressor for all (allantoin) and gcl (glyoxylate) operons; glyoxylate-inducible & -1.93 & 1.10E-03 \\
\hline b0456 & $y b a A$ & DUF1428 family protein & -1.98 & 2.30E-03 \\
\hline
\end{tabular}

be due to a loss of DNA methylation and future work will elucidate the mechanism of these gene expression changes not described in this article. A simple model based on our work and three recent studies is that Dcm has a significant impact on the early stationary phase transcriptome [11-13]. The mechanism of Dcmdependent control of gene expression is not known and remains an enigma. Kahramanoglou et al. provided evidence that Dcm controls expression of the stationary phase specific RNA polymerase subunit rpoS gene and a loss of Dcm generates an increase in RpoS and RpoSdependent gene products [13]. However, we did not observe up-regulation of rpoS expression in 5-azaC treated cells or $\mathrm{dcm}$ knockout cells via DNA microarrays and RT-qPCR (Tables 1, 2 and 3). What could explain the differences in rpoS expression in the absence of the $\mathrm{dcm}$ gene in the two studies? It is possible that genetic differences between the MG1655 strain used in the Kahramanoglou et al. study and the BW25113 strain used in this study could explain the differences in rpoS expression in the absence of $d \mathrm{~cm}$. The genome sequence of BW25113 was released in 2014 [35]. BLASTN searches using the MG1655 rpoS gene and 1000 basepair upstream region as a query indicated the same region is

Table 3 RT-qPCR analysis of gene expression changes in 5-azacytidine treated and dcm knockout Escherichia coli

\begin{tabular}{|c|c|c|c|c|}
\hline Gene & Phase & fc $\left(\log _{2}\right)+$ aza/-aza (array) & fc $\left(\log _{2}\right)+a z a /-a z a(R T-q P C R)$ & fc $\left(\log _{2}\right) \Delta d c m /$ wild-type (RT-qPCR) \\
\hline recA & $\log$ & 2.96 & $3.65^{\mathrm{a}}$ & 0.68 \\
\hline rsml & $\log$ & 1.82 & $3.54^{\mathrm{b}}$ & $2.86^{\mathrm{a}}$ \\
\hline $\operatorname{atpH}$ & early stationary & 1.66 & & 0.64 \\
\hline $\operatorname{csp} B$ & early stationary & 3.40 & & $1.46^{\mathrm{a}}$ \\
\hline $\operatorname{fim} A$ & early stationary & 2.11 & & $1.46^{\mathrm{a}}$ \\
\hline osmE & early stationary & -1.46 & & $-1.79^{\mathrm{a}}$ \\
\hline recA & early stationary & 2.53 & $2.98^{\mathrm{b}}$ & 0.98 \\
\hline rpos & early stationary & 0.69 & 0.035 & 0.17 \\
\hline osmE & stationary & & & $-3.0^{\mathrm{a}}$ \\
\hline rpos & stationary & & & -0.15 \\
\hline
\end{tabular}

${ }^{a} \mathrm{fc}\left(\log _{2}\right)>$ or $<1$ and $p<0.05$ in qPCR experiment

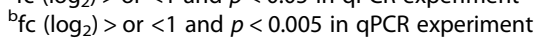


Table 4 Overrepresented functional categories in 5-azacytidine-treated E. coli

\begin{tabular}{llll}
\hline Stage & System & Name & P \\
\hline logarithmic & GOTERM_BP_FAT & DNA repair & $7.85 E-05$ \\
logarithmic & GOTERM_BP_FAT & SOS response & $8.10 E-05$ \\
early stationary & KEGG Pathway & Ribosome & $2.20 E-10$ \\
early stationary & GOTERM_CC_FAT & Organelle inner membrane & $7.40 E-05$ \\
\hline
\end{tabular}

$100 \%$ identical in BW25113 (data not shown). We also sequenced the main rpoS promoter responsible for stationary phase specific expression [36, 37], and there are no sequence differences between MG1655 and BW25113 (Additional file 3). We also sequenced four rpoS transcriptional start sites identified by MendozaVargas et al. [38], and found no genetic differences between the two strains (Additional file 3). In summary, we have no evidence for genetic differences that potentially influence rpoS expression in MG1655 and BW25113. We certainly cannot rule out genetic changes outside of the rpoS loci in the two strains, epigenetic differences in the two strains, or posttranscriptional regulation of rpoS expression via Dcm.

Therefore, our data are not consistent with a model of Dcm-mediated regulation via RpoS and we must consider alternative models. What other molecules are stationary phase specific that could be effector molecules? One possibility is small RNAs, as some small RNAs are up-regulated in E. coli during stationary phase [39], and small RNAs are known to guide DNA methylation in plants [40]. Also, two of the best described Dcm-influenced genes, sugE and osmE, contain 5'CCWGG'3 sites near the -10 region of the promoter. Therefore, a model where Dcm directly influences gene expression by direct methylation of target genes still must be evaluated. DNA methylation could influence gene expression via numerous mechanisms including the alteration of DNA structure and influencing transcription factor binding. With respect to osmE, Regulon DB indicates the transcription factors FIS and IHF bind to the osmE promoter, but the binding sites do not overlap the 5'CCWGG3' site [41]. It is important to note that $\sim 11 \%$ of $E$. coli promoters contain 5'CCWGG3' sites [12]. Yet, most of these genes are not changing in response to DNA methylation loss, and therefore promoter methylation is not likely a common mechanism to control gene expression.

Since we observed gene expression changes in the absence of Dcm, another question concerns the biological consequences of the gene expression changes. As the vast majority of gene expression changes occur at early stationary phase, it is possible that $\mathrm{Dcm}$ has a role in stationary phase biology. During stationary phase of cells grown in liquid culture, $\sim 99 \%$ of the cells die within $7-$
10 days [42]. Subsequently, cells persist for long periods of time where waves of mutations can generate cells that can outcompete their predecessors (growth advantage at stationary phase, GASP). We are currently working to determine if Dcm promotes or reduces GASP.

\section{Conclusions}

In this report, the E. coli transcriptomes of cells grown in the absence and presence of the cytosine DNA methylation inhibitor 5-azaC were compared. 5-azaC was found to be an effective DNA demethylating agent in E. coli. 5-azaC induced expression changes in $63 E$. coli genes. The majority of the changes occurred at early stationary phase and were up-regulations. There are at least two mechanisms by which 5 -azaC can induce gene expression changes. The first pathway is a DNA methylation-independent pathway that likely involves a DNA damage response. The second pathway is a DNA methylation-dependent pathway which occurs in the absence of changes in rpoS expression. The precise mechanism by which cytosine DNA methylation influences gene expression will be the focus of future studies.

\section{Methods}

\section{Bacterial strains and growth}

E. coli K-12 wild-type strain BW25113 and dcm knockout strain JW1944-2 have been previously described [12, 43]. The BW25113 (wild-type strain) genotype is $\mathrm{F}^{-}, \Delta(\operatorname{araD}$-araB) 567, $\Delta$ lacZ4787(::rrnB-3), $\lambda$-, rph-1, $\Delta$ (rhaD-rhaB)568, hsdR415. The JW1994-2 (dcm knockout strain) genotype is $\mathrm{F}^{-}, \Delta(\operatorname{araD}$-araB $) 567$, $\Delta$ lacZ4787(::rrnB-3), $\lambda-, \Delta d c m-735:: k a n, r p h-1, \Delta(r h a D-$ rhaB)568, hsdR415. Cells were grown in LB at $37{ }^{\circ} \mathrm{C}$ with shaking at $250 \mathrm{RPM}$ to logarithmic phase $(\sim 2 \mathrm{~h}$, $\mathrm{A}_{600}$ of $\left.\sim 0.45\right)$, early stationary phase $\left(\sim 8 \mathrm{~h}, \mathrm{~A}_{600}\right.$ of $\sim 2.7)$, and stationary phase $\left(\sim 24 \mathrm{~h}, \mathrm{~A}_{600}\right.$ of 3.8). 5-azaC (Sigma) was dissolved fresh in 1x PBS at $5 \mathrm{mg} / \mathrm{ml}$, sterilized by filtration through a $0.22 \mu \mathrm{M}$ filter, and added to experimental samples at $0.5-50 \mu \mathrm{g} / \mathrm{mL}$. The same volume of $1 \mathrm{x}$ PBS was added to control flasks.

\section{DNA methylation analysis via PspGl digestion}

DNA was isolated from $2 \mathrm{~mL}$ of bacterial cells grown to logarithmic phase and early stationary phase using the Qiagen DNeasy kit. DNA quality and quantity was measured using a NanoDrop 1000 spectrophotometer. To 
assess methylation at $5^{\prime}$ CCWGG3' sites, DNA (0.5$1 \mu \mathrm{g}$ ) was incubated with 10 units of the restriction enzymes BstNI or PspGI for $2 \mathrm{~h}$ at $60{ }^{\circ} \mathrm{C}$ [12]. Reactions were monitored by electrophoresis on $1 \%$ agarose gels and stained with $0.5 \mu \mathrm{g} / \mathrm{mL}$ ethidium bromide or $1 \mathrm{x}$ GelRed (VWR).

\section{Sodium bisulfite sequencing}

$1 \mu \mathrm{g}$ of DNA was treated with sodium bisulfite according to the instructions in the EpiTect Kit (Qiagen). Bisulfite-treated DNA was used as a template for PCR. The conditions were $94{ }^{\circ} \mathrm{C}$ for $2 \mathrm{~min}, 94{ }^{\circ} \mathrm{C}$ for $1 \mathrm{~min}$, $55{ }^{\circ} \mathrm{C}$ for $1 \mathrm{~min}$, and $72{ }^{\circ} \mathrm{C}$ for $1 \mathrm{~min}$ for 30 cycles, followed by one cycle of $72{ }^{\circ} \mathrm{C}$ for $10 \mathrm{~min}$. Primer sequences are osmE-F1-D 5'GAAAAGATAAAATTTT TTTAAAGTTAATT3' and osmE-R1-D5'ACACTCAAAATTCCTACCATATTCTTATT3'. PCR products were inserted into the pGEM-T Easy plasmid (Promega), introduced into E. coli JM109, isolated using the alkaline lysis procedure (Wizard SV kit, Promega), and analyzed by Sanger sequencing (GeneWiz, New Jersey).

\section{Total RNA Isolation}

At logarithmic phase, early stationary phase, and stationary phase, RNA was harvested from $4 \mathrm{~mL}$ of cells using the MasterPure RNA isolation kit according to the manufacturer's instructions (EpiCentre). The optional DNase step was included in all preparations. RNA was analyzed by spectrophotometry on a NanoDrop 1000 spectrophotometer. For microarray experiments, RNA quality was assessed by bioanalysis on a RNA 6000 Nano chip at the University of Rochester Genomics Center. RIN values were between 8 and 10. For RT-qPCR experiments, RNA was analyzed by bioanalysis or traditional agarose gel electrophoresis after heating the RNA for $2 \mathrm{~min}$ at $65{ }^{\circ} \mathrm{C}$ in a solution containing $47.5 \%$ formamide and $0.01 \%$ sodium dodecyl sulfate.

\section{DNA Microarray analysis}

Microarray experiments were performed with RNA from untreated cells and cells treated with $5 \mu \mathrm{g} / \mathrm{mL} 5$-azaC. Total RNA was treated with the reagents in the mRNA Only Prokaryotic mRNA Isolation Kit to reduce rRNA levels and polyadenylate the mRNA according to the manufacturer's instructions (EpiCentre). Modified RNA was used as input for array experiments. cRNA was made in the presence of either Cy3-CTP (RNA from untreated cells) or Cy5-CTP (RNA from 5-azaC-treated cells) using the Quick Amp 2color Labeling Kit (Agilent) according to the manufacturer's instructions. Equal amounts of dye-labeled cRNA were hybridized to E. coli 8*15 K DNA microarrays arrays (Agilent technologies). Microarrays were scanned on an Agilent Microarray Scanner. There were five biological replicates for both the logarithmic phase and early stationary phase samples. Data for non E. coli K-12 genomes on the array were removed prior to analysis. $\mathrm{P}$ values were determined with one-sample t-tests. The data were considered significant if the fold-change was $>$ or $<2$ fold and the BenjaminiHochberg false discovery rate (FDR) was $<0.1$. Pathway analysis was performed using DAVID with the high stringency setting and the same FDR cutoff [44].

\section{RT-qPCR analysis}

RT-qPCR was performed as described previously [11]. Fold-changes were determined using the $\Delta \Delta C T$ method [45]. Three or more independent samples were used for each experiment for all targets except $\operatorname{fim} A(n=2)$. The data were considered significant if the fold change was $>$ or $<2$-fold and the $\mathrm{p}$ value was $<0.05$ in one sample $\mathrm{t}$ tests. Primer sequences are listed below.

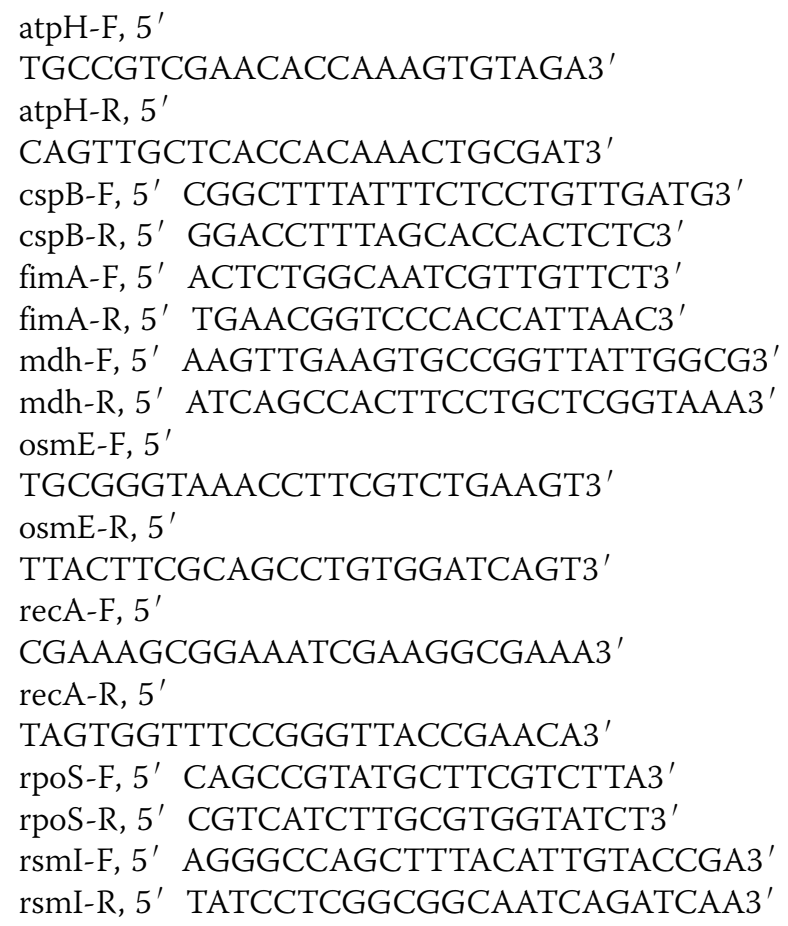

\section{DNA sequencing analysis of the rpos promoter}

PCR was used to amplify the main stationary phase specific rpoS promoter [36, 37] and four rpoS transcription start sites [38]. E. coli BW25113 genomic DNA was used as a template and the Promega GoTaq master mix was used as a source of enzyme, dNTPs, and buffer. The conditions were $94{ }^{\circ} \mathrm{C}$ for $2 \mathrm{~min}, 94{ }^{\circ} \mathrm{C}$ for $1 \mathrm{~min}, 54{ }^{\circ} \mathrm{C}$ for $1 \mathrm{~min}$, and $72{ }^{\circ} \mathrm{C}$ for $45 \mathrm{~s}$ for 30 cycles, followed by one cycle of $72{ }^{\circ} \mathrm{C}$ for $10 \mathrm{~min}$. The PCR products were purified using the Qiagen QIAquick PCR purification kit and analyzed by Sanger DNA sequencing of both strands (GeneWiz, New Jersey). Three forward/reverse primer pairs were utilized; rpoSpF1/rpoSp-R1, rpoSp-F2/rpoSp-R2, rpoSp-F3/rpoSp-R3. The primers sequences are listed below. 
rpoSp-F1, 5' ACCTTGCAGGTGGGTAATG3' rpoSp-R1, 5' GAGATAGGCGTACTGGTTGATG3' rpoSp-F2, 5' GCTACTCAACAACCGCAAATC3' rpoSp-R2, 5' CGTAGGCACTCAGGTAATCATC3' rpoSp-F3, 5' CAGCAAAGGACAGGCAATTATC3' rpoSp-R3, 5' CCTCAACTCCGTTCTCATCAA3'

\section{Statistical analysis}

All statistical tests were performed in R [46].

\section{Additional files}

Additional file 1: Microarray fold-changes, $p$ values, and false discovery rates (FDR) for all E. coli genes from logarithmic phase 5-azaC treated cells. Fold-change is expression in the presence of 5-azaC divided by expression in the absence of 5 -azaC and is $\log _{2}$ transformed. P values are from one sample t-tests, and the FDR is the Benjamini-Hochberg false discovery rate. (CSV $153 \mathrm{~kb}$ )

Additional file 2: Microarray fold-changes, $p$ values, and false discovery rates (FDR) for all E. coli genes from early stationary phase 5 -azaC treated cells. Fold-change is expression in the presence of 5 -azaC divided by expression in the absence of 5 -azaC and is $\log _{2}$ transformed. P values are from one sample t-tests, and the FDR is the Benjamini-Hochberg false discovery rate. (CSV $153 \mathrm{~kb}$ )

Additional file 3: Sanger DNA sequencing analysis of the BW25113 rpoS promoter and transcription start sites. (PDF 509 kb)

\section{Abbreviations}

5-azaC, 5-azacytidine; RT-qPCR, reverse transcription quantitative PCR

\section{Acknowledgements}

We thank Jie Wang for advice on microarray data analysis. We thank Robert O'Donnell, Betsy Hutchison, Rebecca Huss, and Samantha Gage for critical reading of the manuscript.

\section{Funding}

We thank the Geneseo Foundation for financial support of the project.

\section{Availability of data and materials}

Microarray data were deposited in the Gene Expression Omnibus repository (accession number GSE73707).

\section{Authors' contributions}

KTM and RDS conceived and designed the experiments. KTM, AHM, AD, $\mathrm{SMH}, J \mathrm{CL}$, and $\mathrm{SC}$ performed the experiments. All authors were responsible for data analysis. KTM prepared the manuscript. All authors read and approved the final version of the manuscript.

\section{Competing interests}

The authors declare that they have no competing interests.

\section{Consent for publication}

Not applicable.

\section{Ethics approval and consent to participate}

Not applicable.

\section{Author details}

${ }^{1}$ State University of New York at Geneseo, ISC 357, 1 College Circle, Geneseo, NY 14454, USA. ${ }^{2}$ Cornell University, Ithaca, NY 14853, USA.

Received: 14 October 2015 Accepted: 14 June 2016 Published online: 27 June 2016

\section{References}

1. Zemach A, McDaniel IE, Silva P, Zilberman D. Genome-wide evolutionary analysis of eukaryotic DNA methylation. Science. 2010;328:916-9.

2. Sanchez-Romero MA, Cota I, Casadesus J. DNA methylation in bacteria: from the methyl group to the methylome. Curr Opin Microbiol. 2015;25:9-16.

3. Marinus M, Lobner-Olesen A. DNA Methylation. In: Böck A, Curtiss III R, Kaper J, Karp P, Neidhardt F, Nyström T, et al., editors. EcoSal - Escherichia coli and Salmonella: Cellular and Molecular Biology. Washington: ASM Press; 2009. p. 1-88.

4. Marinus MG, Morris NR. Isolation of deoxyribonucleic acid methylase mutants of Escherichia coli K-12. J Bacteriol. 1973;114:1143-50.

5. Hennecke F, Kolmar H, Brundl K, Fritz HJ. The vsr gene product of E. coli K12 is a strand- and sequence-specific DNA mismatch endonuclease. Nature. 1991;353:776-8.

6. Robertson $A B$, Matson SW. Reconstitution of the very short patch repair pathway from Escherichia coli. J Biol Chem. 2012;287:32953-66.

7. Sohail A, Lieb M, Dar M, Bhagwat AS. A gene required for very short patch repair in Escherichia coli is adjacent to the DNA cytosine methylase gene. J Bacteriol. 1990;172:4214-21.

8. Ohno S, Handa N, Watanabe-Matsui M, Takahashi N, Kobayashi Maintenance forced by a restriction-modification system can be modulated by a region in its modification enzyme not essential for methyltransferase activity. J Bacteriol. 2008;190:2039-49.

9. Takahashi N, Naito Y, Handa N, Kobayashi I. A DNA methyltransferase can protect the genome from postdisturbance attack by a restrictionmodification gene complex. J Bacteriol. 2002;184:6100-8.

10. Hattman S, Schlagman S, Cousens L. Isolation of a mutant of Escherichia coli defective in cytosine-specific deoxyribonucleic acid methylase activity and in partial protection of bacteriophage lambda against restriction by cells containing the N-3 drug-resistance factor. J Bacteriol. 1973;115:1103-7.

11. Militello KT, Mandarano AH, Varechtchouk O, Simon RD. Cytosine DNA methylation influences drug resistance in Escherichia coli through increased sugE expression. FEMS Microbiol Lett. 2014;350:100-6.

12. Militello KT, Simon RD, Qureshi M, Maines R, VanHorne ML, Hennick SM, et al. Conservation of Dcm-mediated cytosine DNA methylation in Escherichia coli. FEMS Microbiol Lett. 2012;328:78-85.

13. Kahramanoglou C, Prieto Al, Khedkar S, Haase B, Gupta A, Benes V, et al. Genomics of DNA cytosine methylation in Escherichia coli reveals its role in stationary phase transcription. Nat Commun. 2012;3:886.

14. Goll MG, Kirpekar F, Maggert KA, Yoder JA, Hsieh CL, Zhang X, et al. Methylation of tRNAAsp by the DNA methyltransferase homolog Dnmt2. Science. 2006;311:395-8.

15. Schaefer M, Pollex T, Hanna K, Tuorto F, Meusburger M, Helm M, et al. RNA methylation by Dnmt2 protects transfer RNAs against stress-induced cleavage. Genes Dev. 2010;24:1590-5.

16. Som S, Friedman S. Regulation of EcoRIl methyltransferase: effect of mutations on gene expression and in vitro binding to the promoter region. Nucleic Acids Res. 1994:22:5347-53.

17. Kaminskas E, Farrell AT, Wang YC, Sridhara R, Pazdur R. FDA drug approval summary: azacitidine (5-azacytidine, Vidaza) for injectable suspension. Oncologist. 2005;10:176-82.

18. Stresemann C, Lyko F. Modes of action of the DNA methyltransferase inhibitors azacytidine and decitabine. Int J Cancer. 2008;123:8-13.

19. Yang X, Lay F, Han H, Jones PA. Targeting DNA methylation for epigenetic therapy. Trends Pharmacol Sci. 2010;31:536-46.

20. Barbe J, Gibert I, Guerrero R. 5-Azacytidine: survival and induction of the SOS response in Escherichia coli K-12. Mutat Res. 1986;166:9-16.

21. Lal D, Som S, Friedman S. Survival and mutagenic effects of 5-azacytidine in Escherichia coli. Mutat Res. 1988;193:229-36.

22. Doiron KM, Lavigne-Nicolas J, Cupples CG. Effect of interaction between 5-azacytidine and DNA (cytosine-5) methyltransferase on C-to-G and C-to-T mutations in Escherichia coli. Mutat Res. 1999;429:37-44.

23. Doskocil J, Sorm F. The effects of 5-azacytidine and 5-azauridine on protein synthesis in Escherichia coli. Biochem Biophys Res Commun. 1970;38:569-74.

24. Schaefer M, Hagemann S, Hanna K, Lyko F. Azacytidine inhibits RNA methylation at DNMT2 target sites in human cancer cell lines. Cancer Res. 2009:69:8127-32

25. Ali IK, Ehrenkaufer GM, Hackney JA, Singh U. Growth of the protozoan parasite Entamoeba histolytica in 5-azacytidine has limited effects on parasite gene expression. BMC Genomics. 2007;8:7.

26. Qiu X, Hother C, Ralfkiaer UM, Sogaard A, Lu Q, Workman CT, et al. Equitoxic doses of 5-azacytidine and 5-aza-2'deoxycytidine induce diverse immediate 
and overlapping heritable changes in the transcriptome. PLoS One. 2010;5: e12994.

27. Ringquist S, Smith CL. The Escherichia coli chromosome contains specific, unmethylated dam and dcm sites. Proc Natl Acad Sci USA. 1992;89:4539-43.

28. Bhagwat AS, Roberts RJ. Genetic analysis of the 5-azacytidine sensitivity of Escherichia coli K-12. J Bacteriol. 1987;169:1537-46.

29. Friedman S. Bactericidal effect of 5-azacytidine on Escherichia coli carrying EcoRll restriction-modification enzymes. J Bacteriol. 1982;151:262-8.

30. Krasich R, Wu SY, Kuo HK, Kreuzer KN. Functions that protect Escherichia coli from DNA-protein crosslinks. DNA Repair (Amst). 2015;28:48-59.

31. Frommer M, McDonald LE, Millar DS, Collis CM, Watt F, Grigg GW, et al. A genomic sequencing protocol that yields a positive display of 5methylcytosine residues in individual DNA strands. Proc Natl Acad Sci U S A. 1992;89:1827-31.

32. Salem AM, Nakano T, Takuwa M, Matoba N, Tsuboi T, Terato H, et al. Genetic analysis of repair and damage tolerance mechanisms for DNAprotein cross-links in Escherichia coli. J Bacteriol. 2009;191:5657-68.

33. Nakano T, Morishita S, Katafuchi A, Matsubara M, Horikawa Y, Terato H, et al. Nucleotide excision repair and homologous recombination systems commit differentially to the repair of DNA-protein crosslinks. Mol Cell. 2007;28:147-58.

34. Becket $\mathrm{E}$, Chen F, Tamae C, Miller JH. Determination of hypersensitivity to genotoxic agents among Escherichia coli single gene knockout mutants. DNA Repair (Amst). 2010;9:949-57.

35. Grenier F, Matteau D, Baby V, Rodrigue S. Complete Genome Sequence of Escherichia coli BW25113. Genome Announc. 2014;2:e01038-14.

36. Lange R, Fischer D, Hengge-Aronis R. Identification of transcriptional start sites and the role of ppGpp in the expression of rpoS, the structural gene for the sigma S subunit of RNA polymerase in Escherichia coli. J Bacteriol. 1995;177:4676-80

37. Takayanagi Y, Tanaka K, Takahashi H. Structure of the $5^{\prime}$ upstream region and the regulation of the rpoS gene of Escherichia coli. Mol Gen Genet. 1994:243:525-31.

38. Mendoza-Vargas A, Olvera L, Olvera M, Grande R, Vega-Alvarado L, Taboada $B$, et al. Genome-wide identification of transcription start sites, promoters and transcription factor binding sites in E. coli. PLoS One. 2009;4:e7526.

39. Argaman L, Hershberg R, Vogel J, Bejerano G, Wagner EG, Margalit H, et al. Novel small RNA-encoding genes in the intergenic regions of Escherichia coli. Curr Biol. 2001;11:941-50

40. Matzke MA, Mosher RA. RNA-directed DNA methylation: an epigenetic pathway of increasing complexity. Nat Rev Genet. 2014;15:394-408.

41. Salgado H, Peralta-Gil M, Gama-Castro S, Santos-Zavaleta A, Muniz-Rascado L, Garcia-Sotelo JS, et al. RegulonDB v8.0: omics data sets, evolutionary conservation, regulatory phrases, cross-validated gold standards and more. Nucleic Acids Res. 2013;41:D203-13.

42. Finkel SE. Long-term survival during stationary phase: evolution and the GASP phenotype. Nat Rev Microbiol. 2006;4:113-20.

43. Baba T, Ara T, Hasegawa M, Takai Y, Okumura Y, Baba M, et al. Construction of Escherichia coli K-12 in-frame, single-gene knockout mutants: the Keio collection. Mol Syst Biol. 2006:2:1-11.

44. Dennis Jr G, Sherman BT, Hosack DA, Yang J, Gao W, Lane HC, et al. DAVID: Database for Annotation, Visualization, and Integrated Discovery. Genome Biol. 2003;4:P3

45. Livak KJ, Schmittgen TD. Analysis of relative gene expression data using real-time quantitative PCR and the 2(-Delta Delta C(T)) Method. Methods. 2001;25:402-8.

46. R Core Team. R. A language and environment for statistical computing. Vienna: R Foundation for Statistical Computing; 2015. https://R-project.org.

\section{Submit your next manuscript to BioMed Central and we will help you at every step:}

- We accept pre-submission inquiries

- Our selector tool helps you to find the most relevant journal

- We provide round the clock customer support

- Convenient online submission

- Thorough peer review

- Inclusion in PubMed and all major indexing services

- Maximum visibility for your research

Submit your manuscript at www.biomedcentral.com/submit

) Biomed Central 